\title{
Pain among veterans with spinal cord injury
}

\author{
Philip M. Ullrich, PhD; ${ }^{1-2 *}$ Mark P. Jensen, PhD; ${ }^{2}$ John D. Loeser, MD; ${ }^{3}$ Diana D. Cardenas, MD, MHA; ${ }^{4}$ \\ Frances $\mathbf{M}$. Weaver, $\mathbf{P h D}^{\mathbf{5}}$ \\ ${ }^{1}$ Department of Veterans Affairs (VA) Spinal Cord Injury Quality Enhancement Research Initiative (SCI QUERI), VA \\ Puget Sound Healthcare System, Seattle, WA; Departments of ${ }^{2}$ Rehabilitation Medicine and ${ }^{3}$ Neurological Surgery, \\ University of Washington, Seattle, WA; ${ }^{4}$ Department of Rehabilitation Medicine, University of Miami, Miller School of \\ Medicine, Miami, FL; ${ }^{5}$ VA SCI QUERI, Edward Hines Jr VA Hospital, Hines, IL
}

\begin{abstract}
The Department of Veterans Affairs Veterans Health Administration cares for approximately $15 \%$ of persons with spinal cord injury (SCI) in the United States. However, the nature and characteristics of pain among veterans with SCI are not well understood. This study used a postal survey to compare veterans with SCI and nonveterans with SCI on pain intensity; pain interference; functioning; and other pain, demographic, and medical characteristics. Veterans tended to be older than nonveterans but these groups were otherwise comparable on demographic and medical variables. Veterans were not significantly different from nonveterans on pain intensity or pain interference. Veterans reported lower levels of functioning than nonveterans and higher levels of pain-related catastrophizing. However, differences in functioning between veterans and nonveterans were attributable to age differences between the groups. In summary, differences between veterans with SCI and nonveterans with SCI were few and small in magnitude, suggesting that veterans with SCI are not at greater risk for pain and pain-related problems. However, pain-related catastrophizing may be a particular concern among veterans with SCI.
\end{abstract}

Key words: age, catastrophizing, chronic pain, functioning, pain, pain intensity, pain interference, rehabilitation, spinal cord injury, veterans.

\section{INTRODUCTION}

Most persons with spinal cord injury (SCI) endure chronic pain for years after their acute injuries are healed and rehabilitation is complete. Studies estimate that the prevalence of chronic pain after SCI is more than 75 percent [1-3]. Persons with SCI consistently report average pain levels between 4 and 6 in studies using the $0-10$ numerical rating scale (NRS) [4-5], pain levels that are high enough to warrant comprehensive treatment and prompt follow-up in primary-care settings [6]. Pain is severe, with a strong negative impact on daily functioning, in about one-third of persons with SCI [1-2]. Of significant concern is the finding that once pain conditions following SCI emerge, they tend to persist [3-4] or worsen [2,7] over time, despite the many efforts to treat this pain. In summary, while pain is a ubiquitous, recalcitrant problem among persons with SCI, the degree to which pain has a pronounced effect on functioning is much more variable. Developing a better understanding of subgroups of persons with SCI that may be especially vulnerable to pain-related functional disruptions is critical.

\footnotetext{
Abbreviations: $\mathrm{ANCOVA}=$ analysis of covariance, $\mathrm{ANOVA}=$ analysis of variance, BPI = Brief Pain Inventory, CIQ = Community Integration Questionnaire, CSQ = Coping Strategies Questionnaire, HSR\&D = Health Services Research and Development, NRS $=$ numerical rating scale, $\mathrm{SCI}=$ spinal cord injury, VA = Department of Veterans Affairs, VHA = Veterans Health Administration.

* Address all correspondence to Philip Ullrich, PhD; HSR\&D, 1100 Olive Way, Suite 1400, Seattle, WA 98101; 206-2773911; fax: 206-764-2935. Email: philip.ullrich@va.gov

DOI: 10.1682/JRRD.2008.01.0005
} 
Veterans with SCI are a necessary focus of clinical pain research for several reasons. First, approximately 15 percent of persons with SCI in the United States are veterans, making the Department of Veterans Affairs (VA) Veterans Health Administration (VHA) the largest single network of SCI care in the nation [8]. Second, veterans as a group tend to experience a greater number of socioeconomic and lifestyle risk factors for disease and pain. Compared with the general population, veterans are more likely to be male, older, single, unemployed, and less educated and to have lower income [9]. Third, veterans are also more likely to smoke [9-10] and drink heavily [11]. With this constellation of risk factors, it is not surprising that veterans have more comorbid medical conditions than their counterparts in the general population [9], and thus veterans might be expected to experience greater pain and pain-related problems than nonveterans. In support of this position, prior research has shown older age [12], poorer health status [3], unemployment [5], and lower education [5] to be associated with pain following SCI. However, demographic factors are notoriously inconsistent predictors of pain following SCI [13], making replication of research in this population all the more important.

We are aware of two studies that have compared veterans with SCI and nonveterans with SCI on pain and painrelated factors. Martz and colleagues found that veterans with SCI differed from nonveterans with SCI in ethnicity, marital status, work status, age, and cause of SCI [14]. However, NRS pain intensity scores were similar for veterans and nonveterans with SCI in their sample [14]. Rintala and colleagues found that veterans with SCI were older and reported higher levels of perceived psychological stress [15], as measured by the Perceived Stress Scale [16], than nonveterans with SCI. Life stress has been shown to be an important predictor of pain among persons with medical conditions [17-19]. How veterans with SCI compare with nonveterans in terms of other important pain constructs such as pain interference (the extent to which pain interferes with daily functioning) and catastrophizing (exaggerated negative interpretations of pain, e.g., "my pain is unbearable and will never get better") is unknown. Pain-related catastrophizing is a particularly important variable to study, given its consistent and strong association with pain-related dysfunction in persons with SCI [20] and other medical conditions [21]. Specifically, cognitive errors such as catastrophizing may explain the impact of pain on daily functioning [22]. For example, persons who think "I cannot do anything when I am in pain" may be less likely to engage in important activities of daily living when their pain is high.

The objective of this study was to compare veterans with SCI and nonveterans with SCI on a number of important pain and functioning measures. We hypothesized that, compared with nonveterans, veterans would evidence higher pain intensity scores and lower functioning scores on most if not all measures. We advanced this hypothesis in spite of somewhat contrary findings by Martz and colleagues [14] because we suspected that the NRS as the sole pain instrument in that study may not have been adequate to detect differences between these groups that would be expected based on socioeconomic and disease burden disparities. Furthermore, replication of the Martz et al. study [14] using an array of pain and pain-related measures would represent an important contribution to the scientific literature. We also predicted that catastrophizing would demonstrate strong associations with functioning in our veteran sample, which would replicate findings from studies conducted among nonveterans with SCI.

\section{METHODS}

\section{Participants}

Nonveteran study participants were persons with SCI involved in an ongoing survey of pain, some findings of which are described in a prior report [2]. To address the present study objectives, we mailed additional survey packets, during the same time period as the primary nonveteran study (2005), to veterans with SCI who receive care at SCI Centers at the VA Puget Sound Healthcare System in Seattle, Washington, and the Edward Hines Jr VA Hospital in Hines, Illinois. VA computerized registries were used to generate the list of potential veteran participants. For this survey, questionnaires and consent forms were mailed to 760 individuals. Participants were paid $\$ 25.00$ for completing and returning the forms. Individuals who did not reply within 2 weeks were contacted and reminded to return the questionnaires. All study procedures were approved by the human subjects review committees at the investigators' institutions. Completed surveys and consent forms were received from 132 veterans and 289 nonveterans, for an overall response rate of (55\%, $n=421$ ). Nonveterans showed a better response rate than veterans: 63 versus 44 percent, respectively. 


\section{Measures}

The survey included questions assessing demographic (age, education, employment status, ethnicity, marital status) and medical variables (SCI level, completeness of injury, date of injury).

\section{Pain Intensity}

Participants were asked to rate their average pain intensity during the past week on a 0-10 NRS, with $0=$ "no pain," and 10 = "pain as bad as could be." NRS use has been shown to have good test-retest reliability and adequate validity in associations with other pain measures and treatments [23]. Participants used the NRS to rate overall pain intensity.

\section{Pain Interference}

We used a 12-item version of the Brief Pain Inventory (BPI) [24] modified for persons with SCI [2] to measure the degree to which pain has interfered with daily activities during the past week. Scores on the BPI range from 0 to 10, with higher scores indicating greater pain interference with activities of daily life. This form of the BPI has strong reliability and validity as shown through associations with related constructs [25].

\section{Catastrophizing}

We used the 6-item catastrophizing subscale of the Coping Strategies Questionnaire (CSQ) [26] to assess the frequency of catastrophizing cognitions related to pain. Higher scores indicate more frequent catastrophizing. The catastrophizing subscale of the CSQ has evidenced good reliability and validity in a number of studies [27-28].

\section{Functioning}

We used the Community Integration Questionnaire (CIQ) [29] to measure functioning in three domains: home competency (e.g., shopping, housework), social integration (e.g., leisure outside of home, association with others), and productive activity (e.g., work, education). The CIQ scales have good internal consistency and validity as indicated by associations with relevant constructs [30]. In the present study, the CIQ scales showed good internal consistencies, with Cronbach $\alpha$ between 0.69 and 0.88 . The CIQ has been used as a measure of functioning among persons with SCI [2,31].

\section{Statistical Analyses}

We examined distributions and residual plots of all variables to assess for assumptions of models, skewness, and influential data points. These examinations showed no gross violations of assumptions. We used $t$-tests, chisquare analyses, and analyses of variance (ANOVAs) to compare veterans with nonveterans on key study variables. We used Pearson correlations to examine associations between study variables. Additionally, we conducted tests in which catastrophizing was predicted to mediate associations between pain intensity and functioning. Conventional hierarchical multiple regression procedures for testing mediation were used [32]. In brief, mediation would be demonstrated by the following results from separate regression equations: pain intensity is shown to be associated with catastrophizing and functioning, catastrophizing is shown to be associated with functioning, and the association between pain intensity and functioning is reduced when catastrophizing is included as a control variable. Age and time since SCI were controlled for in these equations.

\section{RESULTS}

We compared respondents excluded because of incomplete data with respondents with complete data on demographic, pain, and SCI characteristics available for analysis to help evaluate the representativeness of our sample, particularly in light of the differential response rates between veterans and nonveterans. We used $t$-tests for continuous data (age, level of injury, time since SCI, pain intensity, pain interference, and catastrophizing) and chi-square analyses for categorical variables (sex, marital status, education, employment status, and completeness of SCI). These tests showed that respondents and nonrespondents were not significantly different on demographic or SCI characteristics.

\section{Demographic and Medical Characteristics}

Demographic and SCI characteristics of the sample are shown in Table 1. Veterans were, on average, approximately 10 years older $(t=6.46, p<0.001)$ and had lived with their SCI about 8 years longer $(t=7.63, p<0.001)$ than nonveterans. Otherwise, veteran and nonveteran groups were similar on demographic and medical characteristics. The sample as a whole tended to be Caucasian, married or living with a partner, unemployed, and with at least a high school education. 
Table 1.

Demographic and spinal cord injury (SCI) characteristics.

\begin{tabular}{lcc}
\hline \multicolumn{1}{c}{ Variable } & Veterans & Nonveterans \\
\hline Current Age (mean \pm SD) & $56.5 \pm 12.8$ & $46.9 \pm 13.7^{*}$ \\
Time Since SCI (mean \pm SD) & $18.9 \pm 12.6$ & $11.0 \pm 9.5^{*}$ \\
C1-C4 Level Injuries (\%) & 6 & 8 \\
C5-T1 Level Injuries (\%) & 37 & 37 \\
T2-S4/S5 Level Injuries (\%) & 57 & 55 \\
Complete Injury (\%) & 44 & 36 \\
Ethnic Group (\%) & & \\
Caucasian & 88 & 89 \\
Hispanic/Chicano & 1 & 3 \\
African American & 9 & 1 \\
Native American & 1 & 4 \\
Asian & 1 & 3 \\
Marital Status (\%) & & \\
Married & 51 & 43 \\
Living with Partner & 5 & 33 \\
Never Married/Widowed & 13 & 13 \\
Separated/Divorced & 31 & \\
Education Level (\%) & & \\
Some High School or Lower & 18 & 38 \\
High School Degree & 42 & \\
College Graduate or Higher & 40 & \\
Employment (\%) & & \\
Working or in School & 82 & \\
Not Working, Not in School & & \\
*p 0.001. & & \\
C = cervical, S = sacral, SD = standard deviation, T thoracic. & \\
\hline
\end{tabular}

\section{Pain and Functioning}

Table 2 shows average scores on pain and functioning measures as a function of veteran versus nonveteran status. Both veterans and nonveterans with SCI reported average pain scores of "moderate" intensity on average, which in VHA clinical settings would trigger comprehensive pain assessment and prompt treatment [6]. Veterans and nonveterans did not differ significantly on pain intensity, pain interference, or home competency scores. Both groups had average pain scores greater than 5 , indicating moderate pain warranting intervention. However, veterans showed higher catastrophizing scores $(t=3.64, p<$ $0.001)$ and lower social integration $(t=1.99, p<0.05)$ and productive activity $(t=3.50, p<0.01)$ scores than nonveterans.

To follow up on these findings, we conducted analyses of covariance (ANCOVAs), repeating the ANOVAs that evidenced significant differences between veterans and
Table 2.

Comparison of veterans and nonveterans with spinal cord injury on key study variables (mean \pm standard deviation).

\begin{tabular}{lcc}
\hline \multicolumn{1}{c}{ Variable } & Veterans & Nonveterans \\
\hline Home Competency (CIQ) & $4.62 \pm 2.73$ & $4.90 \pm 2.72$ \\
Social Integration (CIQ) & $6.16 \pm 2.35$ & $6.93 \pm 2.36^{*}$ \\
Productive Activity (CIQ) & $1.18 \pm 1.43$ & $1.90 \pm 1.78^{\dagger}$ \\
Pain Interference (BPI) & $3.66 \pm 2.96$ & $3.38 \pm 2.64$ \\
Pain Intensity (0-10 NRS) & $5.58 \pm 2.35$ & $5.20 \pm 2.45$ \\
Catastrophizing & $2.70 \pm 0.97$ & $2.21 \pm 1.30^{\ddagger}$ \\
${ }^{*} p<0.05$. & \\
${ }^{\dagger} p<0.01$. & \\
${ }^{\ddagger} p<0.001$. & \\
BPI $=$ Brief Pain Inventory, CIQ $=$ Community Integration Questionnaire, \\
NRS = numerical rating scale.
\end{tabular}

nonveterans but controlling for age and time since SCI. When these variables were controlled, veterans and nonveterans were not significantly different on social integration or productive activity. However, veterans continued to show higher levels of catastrophizing after controlling for age and time since SCI $\left(F_{3,416}=10.32, p<0.01\right)$.

Table 3 shows bivariate correlations between pain and functioning variables, with data for veterans presented separately from data for nonveterans. Pain intensity was significantly associated with reduced functioning and greater interference. Higher levels of catastrophizing were significantly associated with lower productive activity, lower social integration, greater pain interference, and high pain intensity. Associations between pain and functioning variables did not differ greatly between veterans and nonveterans in terms of direction and strength.

To determine whether catastrophizing appeared to mediate associations between pain intensity and functioning, we conducted a series of multiple regression equations. Pain intensity was significantly associated with catastrophizing ( $\beta=0.20, p<0.05)$, social integration $(\beta=-0.20, p<0.05)$, productive activity $(\beta=-0.16, p<$ 0.05 ), and pain interference ( $\beta=0.60, p<0.001$ ) in equations controlling for age and time since SCI. Catastrophizing was significantly associated with social integration $(\beta=-0.18, p<0.05)$, productive activity $(\beta=-0.19, p<$ $0.05)$, and pain interference $(\beta=0.24, p<0.01)$ in equations controlling for age and time since SCI. Finally, when we controlled for catastrophizing, pain intensity was no longer associated with pain interference and functioning, suggesting that catastrophizing mediated associations between pain intensity and functioning. 
Table 3.

Bivariate correlations among study variables, displayed according to veteran/nonveteran status.

\begin{tabular}{lccccc}
\hline \multicolumn{1}{c}{ Variable } & $\mathbf{1}$ & $\mathbf{2}$ & $\mathbf{3}$ & $\mathbf{4}$ & $\mathbf{5}$ \\
\hline 1. Home Competency (CIQ) & - & - & - & - & - \\
2. Social Integration (CIQ) & $0.20^{*} / 0.22^{\dagger}$ & - & - & - & - \\
3. Productive Activity (CIQ) & $0.15^{\ddagger} / 0.22^{*}$ & $0.44^{\dagger} / 0.29^{*}$ & - & - & - \\
4. Pain Interference (BPI) & $-0.05 /-0.06$ & $-0.42^{\dagger} /-0.30^{*}$ & $-0.26^{*} /-0.27^{*}$ & - & - \\
5. Pain Intensity Past Week (0-10 NRS) & $-0.07 / 0.11$ & $-0.20^{*} /-0.19^{*}$ & $-0.16^{\dagger} /-0.21^{*}$ & $0.61^{\dagger} / 0.61^{\dagger}$ & - \\
6. Catastrophizing & $-0.05 / 0.10$ & $-0.19^{*} /-0.14^{\ddagger}$ & $-0.12^{\dagger} /-0.13^{*}$ & $0.19^{*} / 0.37^{\dagger}$ & $0.14^{\ddagger} / 0.27^{*}$ \\
\hline
\end{tabular}

${ }^{*} p<0.01$.

${ }^{\dagger} p<0.001$.

${ }^{\ddagger} p<0.05$.

BPI = Brief Pain Inventory, CIQ = Community Integration Questionnaire, NRS = numerical rating scale.

\section{DISCUSSION}

Most persons with SCI can expect to experience some pain for years following injury, but little is known about which persons with SCI are at greater risk for painrelated disruptions in functioning. This study found little evidence that veterans with SCI are at greater risk for pain-related problems than nonveterans with SCI. Veterans in this sample showed pain intensity scores in the moderate range [33], comparable to scores reported by nonveterans in this sample and to veterans with SCI in other reports [34]. Lack of significant differences in pain intensity between veterans and nonveterans was inconsistent with our hypotheses but was consistent with findings from the one prior study we are aware of that compared veterans and nonveterans with SCI on pain intensity [14].

Veterans with SCI differed significantly from nonveterans on functioning, reporting lower scores on measures of social integration and productive activity. However, our follow-up analyses suggested that these differences were explained by differences in age between samples. The single difference between veterans and nonveterans that remained robust in models controlling for age was the presence of higher levels of catastrophizing among veterans with SCI than among nonveterans with SCI.

Catastrophizing was higher among veterans in this sample, was associated with reduced functioning and higher pain intensity, and appeared to mediate associations between pain intensity and functioning. These findings replicate results of numerous other studies that have demonstrated the importance of catastrophizing in pain and pain-related dysfunction [20-21,35]. Catastrophizing is conceptualized as a mediating factor between pain and functioning in most biopsychosocial models of chronic pain. For example, painful stimuli may activate "pain schemas," or memory patterns related to pain, that support cognitive biases such as catastrophizing [21]. Biases in cognitive-processing can involve enhanced memory for, or attention toward, negatively valenced self- and illnessrelated information [21]. In other words, the effect of catastrophizing may be to heighten the threat of pain while highlighting inadequacies in personal coping resources, with a resultant negative impact on functioning $[21,35]$. The present findings are consistent with prior research among persons with SCI that supports the position that catastrophizing mediates associations between pain and functional outcomes [22].

We must discuss the unexpected finding that our sample of veterans was quite similar to the nonveterans in terms of demographic variables, as well as other pain-related variables. With the exception of age, veterans and nonveterans were similar on demographic factors, although we expected the veterans and nonveterans to differ in terms of marital status, ethnicity, employment, and education, based on findings from large-scale epidemiological studies [9]. The implication is that results of the present study may not generalize well to veterans with SCI as a group. For example, our sample was nearly 90 percent Caucasian, whereas in the general veteran population approximately 80 percent are Caucasian [36]. Ethnicity is a particularly important demographic factor to consider when one interprets results of studies of SCI pain, because non-Caucasian persons with SCI may tend to report higher pain intensity and greater levels of pain interference [37].

On the other hand, the similarities found between veterans and nonveterans in this study may not be a result of sampling problems, but instead may reflect true characteristics of these groups. Martz and colleagues also found that 
veterans with SCI were similar to nonveterans with SCI in terms of pain levels, and they used a sample that demographically well represented the veteran population [14]. In parallel research involving persons with amputations, veterans were similar to nonveterans in pain characteristics [38]. SCI and other physical disabilities may serve to level veteran and nonveteran groups on factors where differences are typically found. In other words, the impact of SCI may outweigh the influence of other factors that typically account for differences between veteran and nonveteran groups. Also, important differences may exist in healthcare services received between these two groups, which could account for similarities in pain characteristics where dissimilarities were expected. Specifically, veterans with SCI receive monthly disability compensation, with additional compensation available to those veterans with greater levels of disability [8]. Compared with nonveterans with SCI, veterans with SCI may have greater access to multidisciplinary care and comprehensive psychosocial and healthcare services [8]. Finally, the lack of large differences between veterans and nonveterans in this study and past research may relate to veterans tending to be older than other patient groups; age may actually represent a protective factor in risk for pain-related problems. In persons with amputation [39] and other persons with chronic pain [40], pain appears to show a weaker association with disability than among younger patients. In other words, while older adults do experience increased incidence of pain, pain-related suffering and disability may attenuate as a function of the aging experience (cf. Molton et al. [39]).

Additional limitations to the study should be noted. Conditions under which the mailed self-report surveys were completed are unknown and could have influenced responses. Additionally, survey response rates may have been affected by the fact that many persons with SCI are unable to write; this point is particularly important to this study given the low numbers of persons with high-level injuries who responded. Administration of self-report questionnaires in controlled settings might be preferable to ensure data integrity and possibly to improve response rates. Also, as in a prior study of veterans with SCI, surveys might be administered by telephone [41]. This study was also limited by the low number of respondents with higher-level cervical injuries. Veterans were less likely to respond to the survey questionnaire, again raising questions about how well these results might generalize to the veteran population as a whole.

\section{CONCLUSIONS}

Findings from this study confirm prior reports that pain among veterans with SCI, while at clinically significant levels, may not be greater than pain found among nonveterans. Furthermore, results suggest that painrelated catastrophizing may be a particular concern in this group. Future research might examine these models with prospective and experimental designs, allowing for more careful examinations of causality. In clinical settings, researchers may find it important to assess and manage catastrophizing as a factor important to the experience of pain, especially the impact of pain on functioning. Cognitive behavioral strategies are known to be effective in the management of pain-related catastrophizing in numerous populations with chronic illness [42]. Catastrophizing may be one factor of relevance in paintreatment-matching paradigms that have been proposed for patients with SCI [42].

\section{ACKNOWLEDGMENTS}

We gratefully acknowledge the contributions by Rob Hendricks, PhD, Spinal Cord Injury and Disorders Service, VA, Seattle, Washington; and data collection and database management by Amy Hoffman, Lindsay Washington, Emily Phelps, Laura Nishimura, Kristin McArthur, Kevin Gertz, Noel Pereyra-Johnston, Silvia Amtmann, Joe Skala, and Kerry Madrone, University of Washington School of Medicine Department of Rehabilitation Medicine, Seattle, Washington.

This material is based on work supported in part by grant P01 HD33988 from the National Institutes of Health, National Institute of Child Health and Human Development, National Center for Rehabilitation Research; grant H133N00003 from the National Institute on Disability and Rehabilitation Research, Office of Special Education and Rehabilitative Services, U.S. Department of Education; grant SCT 01-169 from the VA, VHA, Health Services Research and Development (HSR\&D) Service, SCI Quality Enhancement Research Initiative.

This article presents the views of the authors; it does not necessarily represent the views or policies of the VA or the HSR\&D Service.

The authors have declared that no competing interests exist. 


\section{REFERENCES}

1. Finnerup NB, Johannesen IL, Sindrup SH, Bach FW, Jensen TS. Pain and dysesthesia in patients with spinal cord injury: A postal survey. Spinal Cord. 2001;39(5):256-62. [PMID: 11438841]

2. Jensen MP, Hoffman AJ, Cardenas DD. Chronic pain in persons with spinal cord injury: A survey and longitudinal study. Spinal Cord. 2005;43(12):704-12. [PMID: 15968299]

3. Siddall PJ, McClelland JM, Rutkowski SB, Cousins MJ. A longitudinal study of the prevalence and characteristics of pain in the first 5 years following spinal cord injury. Pain. 2003;103(3):249-57. [PMID: 12791431]

4. Cruz-Almeida Y, Martinez-Arizala A, Widerström-Noga EG. Chronicity of pain associated with spinal cord injury: A longitudinal analysis. J Rehabil Res Dev. 2005;42(5): 585-94. [PMID: 16586184]

5. Turner JA, Cardenas DD, Warms CA, McClellan CB. Chronic pain associated with spinal cord injuries: A community survey. Arch Phys Med Rehabil. 2001;82(4):501-9. [PMID: 11295011]

6. Veterans Health Administration. 2005. Pain as the 5th vital sign toolkit. October 2000, revised edition. Geriatrics and Extended Care Strategic Healthcare Group, National Pain Management Coordinating Committee. Available from: http:// www.vachronicpain.org/Downloads/pain5thvitalsignv2.PDF/. Accessed December 2007.

7. Rintala DH, Hart KA, Priebe MM. Predicting consistency of pain over a 10-year period in persons with spinal cord injury. J Rehabil Res Dev. 2004;41(1):75-88. [PMID: 15273900]

8. Department of Veterans Affairs Office of Public Affairs [home page on the Internet]. Washington (DC): Department of Veterans Affairs; c2008 [updated 2007 Aug 20; cited 2008 Feb]. Fact sheet: VA and spinal cord injury; [about 6 screens]. Available from: http://www1.va.gov/opa/fact/ spinalcfs.asp/.

9. Larson RJ, Welch HG. Risk for increased utilization and adverse health outcomes among men served by the Veterans Health Administration. Mil Med. 2007;172(7):690-96. [PMID: 17691680$]$

10. McKinney WP, McIntire DD, Carmody TJ, Joseph A. Comparing the smoking behavior of veterans and nonveterans. Public Health Rep. 1997;112(3):212-18. [PMID: 9160055]

11. Winkleby MA, Fleshin D. Physical, addictive, and psychiatric disorders among homeless veterans and nonveterans. Public Health Rep. 1993;108(1):30-36. [PMID: 8434094]

12. Werhagen L, Budh CN, Hultling C, Molander C. Neuropathic pain after traumatic spinal cord injury-Relations to gender, spinal level, completeness, and age at the time of injury. Spinal Cord. 2004;42(12):665-73. [PMID: 15289801]
13. Siddall PJ, Loeser JD. Pain following spinal cord injury. Spinal Cord. 2001;39(2):63-73. [PMID: 11402361]

14. Martz E, Livneh H, Priebe M, Wuermser LA, Ottomanelli L. Predictors of psychosocial adaptation among people with spinal cord injury or disorder. Arch Phys Med Rehabil. 2005;86(6):1182-92. [PMID: 15954058]

15. Rintala DH, Robinson-Whelen S, Matamoros R. Subjective stress in male veterans with spinal cord injury. J Rehabil Res Dev. 2005;42(3):291-304. [PMID: 16187242]

16. Cohen S, Kamarck T, Mermelstein R. A global measure of perceived stress. J Health Soc Behav. 1983;24(4):385-96. [PMID: 6668417]

17. Craufurd DI, Creed F, Jayson MI. Life events and psychological disturbance in patients with low back pain. Spine. 1990;15(6):490-94. [PMID: 2144912]

18. Lampe A, Doering S, Rumpold G, Solder E, Krismer M, Kantner-Rumplmair W, Schubert C, Sollner W. Chronic pain syndromes and their relation to childhood abuse and stressful life events. J Psychosom Res. 2003;54(4):361-67. [PMID: 12670615]

19. Martine PR, Soon K. The relationship between perceived stress, social support and chronic headaches. Headache. 1993;33(6):307-14. [PMID: 8349473]

20. Turner JA, Jensen MP, Warms CA, Cardenas DD. Catastrophizing is associated with pain intensity, psychological distress, and pain-related disability among individuals with chronic pain after spinal cord injury. Pain. 2002;98(1-2):127-34. [PMID: 12098624]

21. Pincus T, Morley S. Cognitive-processing bias in chronic pain: A review and integration. Psychol Bull. 2001;127(5): 599-617. [PMID: 11548969]

22. Ullrich PM, Jensen MP, Loeser JD, Cardenas DD. Catastrophizing mediates associations between pain severity, psychological distress, and functional disability among persons with spinal cord injury. Rehabil Psychol. 2007;52(4): 390-98.

23. Jensen MP, Turner JA, Romano JM, Fisher LD. Comparative reliability and validity of chronic pain intensity measures. Pain. 1999;83(2):157-62. [PMID: 10534586]

24. Cleeland CS, Ryan KM. Pain assessment: Global use of the Brief Pain Inventory. Ann Acad Med Singapore. 1994; 23(2):129-38. [PMID: 8080219]

25. Raichle KA, Osborne TL, Jensen MP, Cardenas D. The reliability and validity of pain interference measures in persons with spinal cord injury. J Pain. 2006;7(3):179-86. [PMID: 16516823]

26. Rosenstiel AK, Keefe FJ. The use of coping strategies in chronic low back pain patients: Relationship to patient characteristics and current adjustment. Pain. 1983;17(1): 33-44. [PMID: 6226916]

27. Geisser ME, Robinson ME, Henson CD. The Coping Strategies Questionnaire and chronic pain adjustment: A 
conceptual and empirical reanalysis. Clin J Pain. 1994; 10(2):98-106. [PMID: 8075472]

28. Robinson ME, Riley JL 3rd, Myers CD, Sadler IJ, Kvaal SA, Geisser ME, Keefe FJ. The Coping Strategies Questionnaire: A large sample, item level factor analysis. Clin J Pain. 1997;13(1):43-49. [PMID: 9084951$]$

29. Willer BS, Rosenthal M, Kreutzer J, Gordon W, Rempel R. Assessment of the community integration following rehabilitation for traumatic brain injury. J Head Trauma Rehabil. 1993;8:75-87.

30. Sander A, Fuchs K, High WM Jr, Hall KM, Kreutzer JS, Rosenthal M. The Community Integration Questionnaire revisited: An assessment of factor structure and validity. Arch Phys Med Rehabil. 1999;80(10):1303-8. [PMID: 10527092] Erratum in: Arch Phys Med Rehabil. 1999;80(12):1608.

31. Cairns DM, Adkins RH, Scott MD. Pain and depression in acute traumatic spinal cord injury: Origins of chronic problematic pain? Arch Phys Med Rehabil. 1996;77(4):329-35. [PMID: 8607754

32. Baron RM, Kenny DA. The moderator-mediator distinction in social psychological research: Conceptual, strategic, and statistical considerations. J Pers Soc Psych. 1986;51(6): 1173-82. [PMID: 3806354]

33. Hanley MA, Masedo A, Jensen MP, Cardenas D, Turner JA. Pain interference in persons with spinal cord injury: Classification of mild, moderate, and severe pain. J Pain. 2006;7(2):129-33. [PMID: 16459278]

34. Widerström-Noga EG, Felipe-Cuervo E, Yezierski RP. Relationships among clinical characteristics of chronic pain after spinal cord injury. Arch Phys Med Rehabil. 2001;82(9):1191-97. [PMID: 11552190]

35. Sullivan MJ, Thorn B, Haythornthwaite JA, Keefe F, Martin M, Bradley LA, Lefebvre JC. Theoretical perspectives on the relation between catastrophizing and pain. Clin J Pain. 2001;17(1):52-64. [PMID: 11289089]

36. Department of Veterans Affairs [home page on the Internet]. Washington (DC): Department of Veterans Affairs; c2008 [updated 2007 Oct 25; cited 2008 Jan 7] VA benefits and health care utilization; [about 1 screen]. Available from: http://www1.va.gov/vetdata/docs/4X6 fall07 sharepoint.pdf/.

37. Cardenas DD, Bryce TN, Shem K, Richards JS, Elhefni H. Gender and minority differences in the pain experience of people with spinal cord injury. Arch Phys Med Rehabil. 2004;85(11):1774-81. [PMID: 15520972]

38. Sherman RA, Sherman CJ. A comparison of phantom sensations among amputees whose amputations were of civilian and military origins. Pain. 1985;21(1):91-97. [PMID: 3982838]

39. Molton IR, Jensen MP, Ehde DM, Smith DG. Phantom limb pain and pain interference in adults with lower extremity amputation: The moderating effects of age. Rehabil Psychol. 2007;52(3):272-79.

40. Rustoen T, Wahl AK, Hanestad BR, Lerdal A, Paul S, Miaskowski C. Age and the experience of chronic pain: Differences in health and quality of life among younger, middle-aged, and older adults. Clin J Pain. 2005;21(6): 513-23. [PMID: 16215337]

41. Rintala DH, Holmes SA, Fiess RN, Courtade D, Loubser PG. Prevalence and characteristics of chronic pain in veterans with spinal cord injury. J Rehabil Res Dev. 2005:42(5); 573-84. [PMID: 16586183]

42. Ehde DM, Jensen MP. Feasibility of a cognitive restructuring intervention for treatment of chronic pain in persons with disabilities. Rehabil Psychol. 2004;49(3):254-58.

Submitted for publication January 7, 2008. Accepted in revised form March 18, 2008. 